\title{
OPTIMALISASI PERAN KELUARGA DALAM MENGURANGI RESIKO NEGLECT PADA LANSIA
}

\author{
Optimization The Role Of Family In Reducing Neglect Risk On Elderly \\ Fitri Firranda Nurmalisyah ${ }^{1}$,Desy Siswi Anjarsari ${ }^{1}$, Zuliani $^{2}$, Dyah Pitaloka ${ }^{3}$ \\ ${ }^{1}$ Sekolah Tinggi Ilmu Kesehatan Pemkab Jombang \\ ${ }^{2}$ Universitas Pesantren Darul Ulum Jombang \\ ${ }^{3}$ Sekolah Tinggi Ilmu Kesehatan NU Tuban \\ Email: fitriffirranda27@gmail.com
}

\begin{abstract}
ABSTRAK
Menjadi tua merupakan suatu proses alamiah yang berarti seseorang telah melalui tahap-tahap kehidupannya, yang dimulai dari neonatus, toddler, pra school, school, remaja, dewasa dan lansia. Tahap berbeda ini di mulai baik secara biologis maupun psikologis. Kondisi yang dialami oleh lansia dengan pertambahan usia dan perubahanperubahan kondisi tubuh pada lansia, menyebabkan lansia dikategorikan dalam kelompok resiko tinggi. Perubahanperubahan yang terjadi pada lansia baik perubahan fisiologis maupun psikososial menyebabkan lansia mengalami kelemaham dan keterbatasan fungsi. Perubahan fungsi fisiologik berupa keterbatasan, kelemahan dan ketergantungan akan mempengaruhi kondisi psikososial lansia berupa gangguan atau perubahan fungsi psikososial. Perubahan fungsi psikososial pada lansia akan berdampak terhadap terjadinya kerusakan fungsi psikososial pada lansia. Kerusakan fungsi psikososial menjadi faktor resiko bagi lansia. Kerusakan fungsi psikososial pada lansia menjadi faktor resiko terhadap kejadian pengabaian pada lansia. Tujuan dari pengabdian masyarakat ini adalah menanggulangi permasalahan pengabaian lansia yang sering terjadi di masyarakat. Untuk mencegah terjadinya neglect pada lansia, maka perlu diberikan pendidikan kesehatan tentang neglect atau pengabaian lansia agar keluarga dapat melakukan perawatan pada lansia, sehingga tidak terjadi neglect atau pengabaian pada lansia.
\end{abstract}

Kata kunci : peran keluarga, neglect, lansia

\begin{abstract}
Being old is a natural process which means that someone has gone through the stages of his life, starting with neonates, toddlers, pre-schoolers, schools, adolescents, adults and the elderly. This different stage starts both biologically and psychologically. The condition experienced by the elderly with age and changes in body conditions in the elderly, causes the elderly to be categorized in the high risk group. Changes that occur in the elderly both physiological and psychosocial changes cause the elderly to experience weakness and limited function. Changes in physiological functions in the form of limitations, weaknesses and dependencies will affect the psychosocial condition of the elderly in the form of disorders or changes in psychosocial functions. Changes in psychosocial function in the elderly will have an impact on the occurrence of damage to psychosocial functions in the elderly. Damage to psychosocial function is a risk factor for the elderly. Damage to psychosocial function in the elderly is a risk factor for the incidence of neglect in the elderly. The purpose of this community service is to overcome the problem of neglecting the elderly that often occurs in the community. To prevent neglect in the elderly, health education needs to be given about neglect or neglect of the elderly so that families can take care of the elderly, so there is no neglect or neglect in the elderly.
\end{abstract}

Keywords: family role, neglect, elderly

\section{Pendahuluan}

Usia lanjut adalah suatu kejadian yang pasti akan dialami oleh semua orang yang dikaruniai usia panjang, terjadinya tidak bisa dihindari oleh siapapun, namun manusia dapat berupaya untuk menghambat kejadiannya (Bandiyah, 2009).

Menua adalah proses suatu keadaan yang terjadi di dalam kehidupan manusia. Proses menua merupakan proses sepanjang hidup yang tidak hanya dimulai dari suatu 
waktu tertentu, tetapi dimulai sejak permulaan kehidupan. Menjadi tua merupakan proses alamiah yang berarti seseorang telah melalui tahap-tahap kehidupannya, yaitu neonatus, toddler, pra school, school, remaja, dewasa dan lansia. Tahap berbeda ini di mulai baik secara biologis maupun psikologis (Padila, 2013).

Kondisi yang dialami oleh lansia dengan pertambahan usia dan perubahanperubahan kondisi tubuh pada lansia, menyebabkan lansia dikategorikan dalam kelompok resiko tinggi. Perubahanperubahan yang terjadi pada lansia baik perubahan fisiologik maupun psikososial menyebabkan lansia mengalami kelemaham dan keterbatasan fungsi. Perubahan fungsi fisiologik berupa keterbatasan, kelemahan dan ketergantungan akan mempengaruhi kondisi psikososial lansia berupa gangguan atau perubahan fungsi psikososial. Perubahan fungsi psikososial pada lansia akan berdampak terhadap terjadinya kerusakan fungsi psikososial pada lansia. Kerusakan funsi psikososial menjadi faktor resiko bagi lansia. Kerusakan fungsi psikososial pada lansia menjadi faktor resiko terhadap kejadian pengabaian pada lansia.

Berdasarkan data dari Dinas Kesehatan Kabupaten Jombang pada tahun 2016 didapatkan bahwa data jumlah lansia tertinggi di Puskesmas Peterongan Jombang sejumlah 10.930 orang, Puskesmas Perak sejumlah 9.736 orang, Puskesmas Mojowarno sejumlah 9.618 orang, Puskesmas Bareng sejumlah 9.570 orang, Puskesmas Bandar Kedungmulyo sejumlah 8.885 orang (Dinas Kesehatan Jombang, 2016).

Namun, dengan semakin bertambahnya jumlah penduduk di Indonesia yang ditunjukkan oleh data-data diatas, setidaknya dapat diketahui permasalahan- permasalahan yang harus dihadapi oleh pemerintah juga bertambah.
Masalah- masalah tersebut berkaitan dengan masalah kehidupan dan penghidupan seperti perumahan, ekonomi, kesehatan, mental, sosial, dan pekerjaan (Demartoto, 2006). Lansia terlantar, dalam hal ini merupakan salah satu dampak yang muncul akibat pertambahan jumlah penduduk dan meningkatnya angka harapan hidup yang telah diuraikan sebelumnya. Kerentanan, ketidakmampuan, serta rendahnya mobilitas, bergaining position, dan stigma lainnya yang ada pada lainsia sedikit banyak memberikan pandangan kepada masyarakat bahwasanya masamasa lansia adalah masa-masa yang sangat berat di zaman ini.

Keluarga, merupakan sebuah lembaga yang seharusnya memberi kasih sayang, dukungan ekonomi, serta perawatan kesehatan seperti yang dikatakan oleh Friedman (1998: dalam Setiawati \& Santun). Namun, dalam kenyataannya lembaga sering kali mengabaikan tugas-tugas dan fungsi utamanya; fungsi afektif; fungsi ekonomi; dan fungsi perawatan kesehatan. Keluarga, yang seharusnya menjadi satu-satunya lembaga yang merawat dan menjaga eksistensi lansia justru mengabaikannya dan membuangnya ke tempat-tempat penitipan lansia dengan dalih manajemen yang lebih baik dan lebih terarah. Hal ini lantas menimbulkan dampak dan gejala ledakan lansia terlantar, belum lagi ketidakmampuan lembaga- lembaga PLSU (Penanganan Sosial Lanjut Usia) untuk menampung jumlah penduduk lansia yang tiap harinya mengalami peningkatan, sedangkan banyak dari lansia yang telah ada tidak menunjukan kecenderungan jumlah penurunan karena angka harapan hidup yang tinggi. Karena itulah, sering kali banyak lansia- lansia terlantar, hidup di jalanan dan bekerja serabutan. Dari data yang kami peroleh menunjukkan bahwa saat ini terdapat 2,4 juta penduduk lansia di 
Indonesia yang hidup terlantar (BPS, 2010). Tak hanya itu, dari hasil penelitian yang dilakukan oleh Yasa (2002) menunjukkan bahwa penelantaran tersebut terjadi akibat peningkatan pesat jumlah penduduk lansia di Indonesia yang tidak diimbangi oleh peningkatan jumlah program-program jaminan sosial bagi penduduk lansia.

Ogburn, menjelaskan bahwa salah satu sebab lunturnya nilai-nilai luhur keluarga yang kemudian mendorong fenomena penelantaran lainsia dalam hal ini kemudian dipahami oleh Friedman sebagai fungsi-fungsi keluarga ialah karena desakan atau pengaruh kekotaan (modernisasi). Hal tersebut ditandai dengan semakin majunya teknologi akibat adanya inovasi (penemuan-penemuan baru) sehingga memunculkan suatu suatu pola kehidupan masyarakat baru (kebudayaan baru). Dengan adanya modernisasi tersebut mengakibatkan fungsi dari keluarga yang sesungguhnya menjadi hilang (tidak berfungsi lagi), kemudian muncullah suatu tipe kehidupan keluarga baru yang lebih menekankan fungsi-fungsi kepribadian (individualis) (Ogburn, 1976).

Dukungan anggota keluarga memberikan contoh yang baik pada lansia, seperti melakukan atau menyarankan perilaku yang sehat. Anggota keluarga terlalu menjaga atau mendukung lansia dalam melakukan sesuatu yang diinginkannya (Azizah, 2011).

Memahami fenomena yang terjadi di masyarakat saat ini, maka pelaksana tertarik untuk melakukan pengabdaian masyarakat dengan judul "Optimalisasi Peran Keluarga Dalam Mengurangi Resiko Neglect Pada Lansia”. Kegiatan tersebut diharapkan bisa mengurangi angka pengabaian lansia di masyarakat yang merupakan salah satu bentuk pengabdian masyarakat Dosen STIKES PEMKAB Jombang

\section{Metode}

Metode yang digunakan dalam pengabdian Langkah pelaksanaan dalam kegiatan pengabdian tersebut adalah sebagai berikut.

a. Survei Lapangan

Survei lapangan di Desa Sentul Kecamatan Ploso Kabupaten Jombang bertujuan untuk mengamati situasi dan keadaan masyarakat yang direncakan sebagai objek sasaran.

b. Koordinasi dengan pihak kepala desa Berkoordinasi dengan pihak kepala Desa Sentul Kecamatan Ploso Kabupaten Jombang untuk menentukan kesepakatan mufakat antara waktu dan tempat pelaksanaan kegiatan pengabdian masyarakat.

c. Sosialisasi Program

Sosialisasi program bertujuan untuk memberi informasi tentang rencana serangkaian pelaksanaan program yang disampaikan kepada warga masyarakat Desa Sentul Kecamatan Ploso Kabupaten Jombang untuk mengikuti kegiatan pengabdian masyarakat.

d. Pelaksanaan Program

berupa pendidikan kesehatan dan simulasi pengabaian lansia.

\section{Hasil}

1. Kegiatan pengabdian masyarakat berjalan dengan lancar

2. Materi yang disampaikan oleh Fitri Firranda N, S. Kep., Ns selaku pembicara dan pelaksana yaitu Perawatan Lansia dan neglect atau pengabaian lansia

3. Kegiatan berjalan selama 2 jam

4. Peserta penyuluhan yang terdiri dari warga desa yang merawat lansia sebanyak 30 orang

5. Peserta cukup antusias dan komunikatif dengan pembicara

6. Pertanyaan yang diajukan oleh peserta penyuluhan cukup bervariasi, mulai dari keadaan kegiatan yang diberikan untuk 
lansia, psikologis lansia dan bahaya pengabaian lansia.

7. Warga paham tentang perawatan lansia dan dan neglect atau pengabaian lansia

\section{Pembahasan}

Perawatan lansia dan neglect atau pengabaian lansia merupakan materi yang perlu disampaikan, karena

- Lansia merupakan individu yang membutuhkan perawatan dari keluarga

- Beban keluarga dalam merawat lansia

- Stress yang sering terjadi pada lansia jika keluarga tidak tahu tentang perawatan lansia

- Lansia dengan keluarga yang tidak kondusif beresiko terjangkit penyakit lebih tinggi dibandingkan dengan lansia yang tinggal dengan keluarga kondusif/ mengerti kondisi.

\section{Kesimpulan}

Pendidikan tentang perawatan lansia dan neglect atau pengabaian lansia perlu diberikan sebagai upaya memperbaiki kondisi lansia khususnya kondisi psikologis lansia yang dirawat keluarga.

\section{Saran}

Masih diperlukan tindak lanjut petugas kesehatan dari pengabdian masyarakat ini agar penanganan angka pengabaian lansia bisa berkurang dan kualitas hidup lansia bisa lebih baik.

\section{Referensi}

Azizah, Lilik M. (2011). Keperawatan Lanjut Usia. Yogyakarta: Graha Ilmu.

Bandiyah. 2009. Lanjut Usia dan Keperawatan Gerontik. Yogyakarta. Nuha Medika.

Bandiyah. 2012. Psikologi Kesehatan. Yogyakarta. Nuha Medika

Dinas Kesehatan Jombang. 2016. Jumlah lansia di Jombang.

Padila. 2013. Buku Ajar Keperawatan Gerontik. Yogyakarta. Nuha Medika. 